\title{
Bent-shaped Liquid Crystal Dimers: Effect of Molecular Shapes on Mesomorphic Properties
}

\author{
Bong-Keun So, Soo-Min Lee, Ok-Byung Choi, ${ }^{+}$Hwan Myung Lee, ${ }^{;}$Jin-Young Lee, ${ }^{\dagger}$ Seong-Jo Kim, ${ }^{\dagger}$ \\ Eun-Hee Cha, ${ }^{\dagger}$ Ran Hee Kim, ${ }^{\dagger}$ and Joo-Hoon Park ${ }^{\div-}$ \\ Department of Chemistry, Hamam Lniversity, Taejon 306-791, Korea \\ ${ }^{\dagger}$ College of Natural Science, Hoseo Lniversity Choongnam 336-795, Korea. ${ }^{\star}$ E-mail: jhparkathoseo.edu \\ Received March 19, 2009, Accepted June 2, 2009
}

Key Wonds: Bent-shaped liquid crỵstal. Dimesogenic compounds

For the past two decades, the liquid crystal compounds having obtuse and acute angled configurations have been attracting attention. ${ }^{1 . \hat{*}}$ Through the sterically induced packing of the bent molecules new smectic modifications can occur. which have no counterpart in the field of calamitic liquid crystals. Especially, the recent discovery of banana-shaped liquid crystal materials i.e. mesogenic compounds bent symmetrically along the middle of the molecules ${ }^{3.4}$ have boosted up the studies in this field. Niori et al ${ }^{5}$ reported a liquid cry stallinity for the compounds having linear. bent. and U-shaped hydrogen bonded mesogenic cores.

Generally dimers with an even-numbered spacer exhibit SmA phases and/or nematic phases while homologous compounds with odd-numbered spacer exhibit SmC phases. Contrarily to this a mesomorphism in the bent-shaped symmetric dimers with odd-numbered flexible spacer has been reported recently ${ }^{6-8}$ Therefore. we have designed and synthesized three bent-shaped liquid crystal dimmers. All of these molecules have two Schiff base mesogenic units with dodecyloxy terminal chain $\left(-\mathrm{OC}_{\left.1-\mathrm{H}_{25}\right)}\right.$ symmetrically linked via 2-hydroxypropylene short spacer. The three compounds differ only in the patterns to join the spacer and mesogenic units. In these compounds the central spacer is attached on the 4- 3-. and 2-position of two mesogenic units and they are represented as the $1 \mathrm{~S}_{12-p a r a .} 1 \mathrm{~S}_{1-\text { meta }}$ and $1 \mathrm{~S}_{1=-o r t h o}$ respectively: Figure 1 shows the most probable atomic configurations of the compounds.
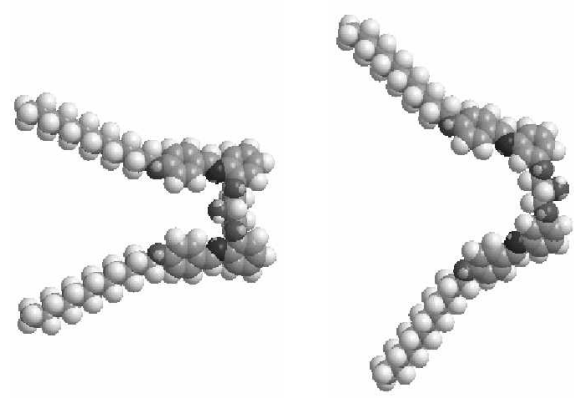

$1 \mathrm{~S}_{t 2-o r t h o}$
$1 S_{12-I n t a t a}$

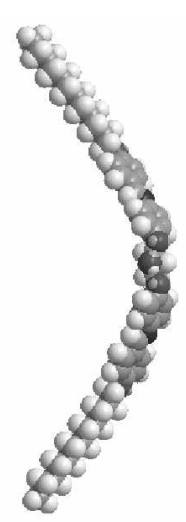

1S

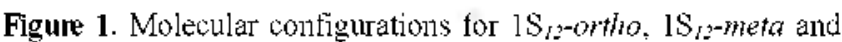
1S $I 3$-para compounds.

\section{Experiment Section}

The synthesis process for the designed molecules is outlined in the Schemel. The dinitro compounds (NPP- $o,-m,-p$ ) were firstly synthesized by reacting epichlorohydrin with $o$-. $m-$. $p$-nitrophenols, respectively, according to the sinular method described in the literature. ${ }^{8}$ The dinitro compounds thus obtained were then converted to the corresponding diamines (APP- $o,-m,-p$ ) by the reduction reaction with hydrazine monohydrate in the presence of palladium on active carbon. In the meanwhile the aldehyde $\mathrm{BA}_{2}$ was obtained from the conventional etherification of 4-hydroxybenzaldehyde with a dodecyl bromide. Finally. the diamines APP $-o$. APP $-m$ and APP- $p$ were reacted with the aldehyde $\mathrm{BA}_{I_{-}}$using PTSA<smiles>CC(C)(C)CC(O)COc1ccc([N+](=O)[O-])cc1OCC(O)CCl</smiles>

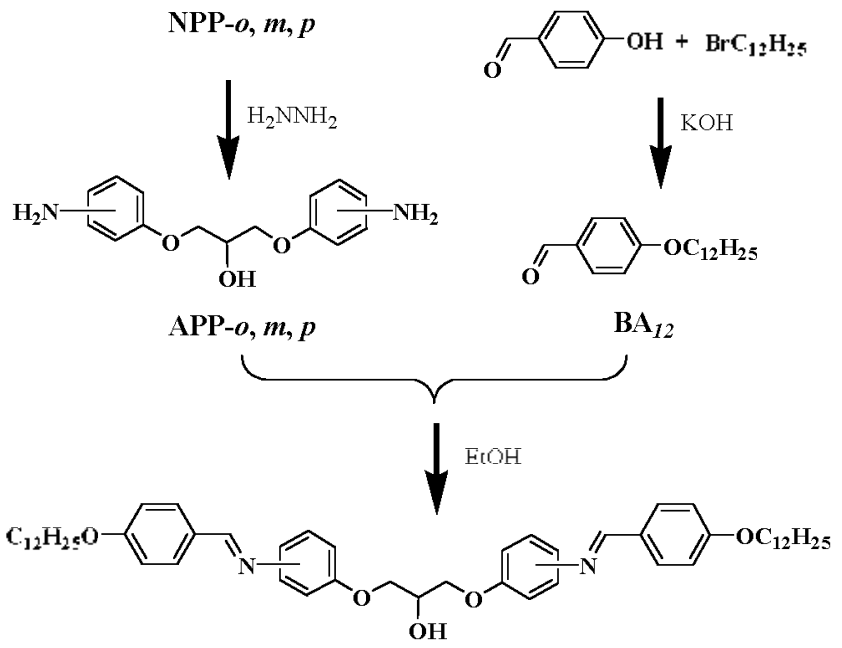

$1 \mathrm{~S}_{I Y}$-ortho, -meta, -para

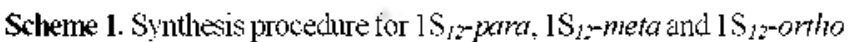
compounds. 


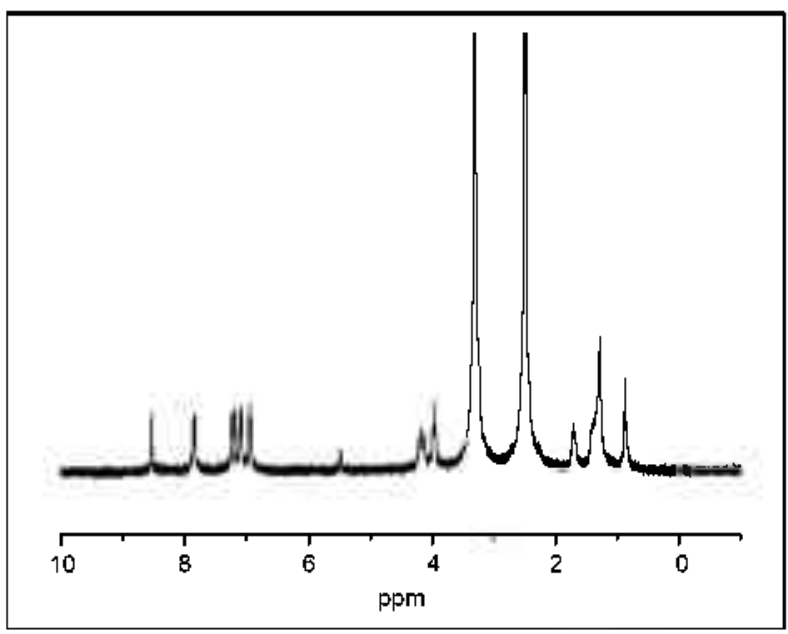

Figure 2. ${ }^{1} \mathrm{H}$ NMR spectrum of $1 \mathrm{~S}_{l 2}-$ para $\left(\mathrm{DMSO}_{-} d_{6}\right)$.

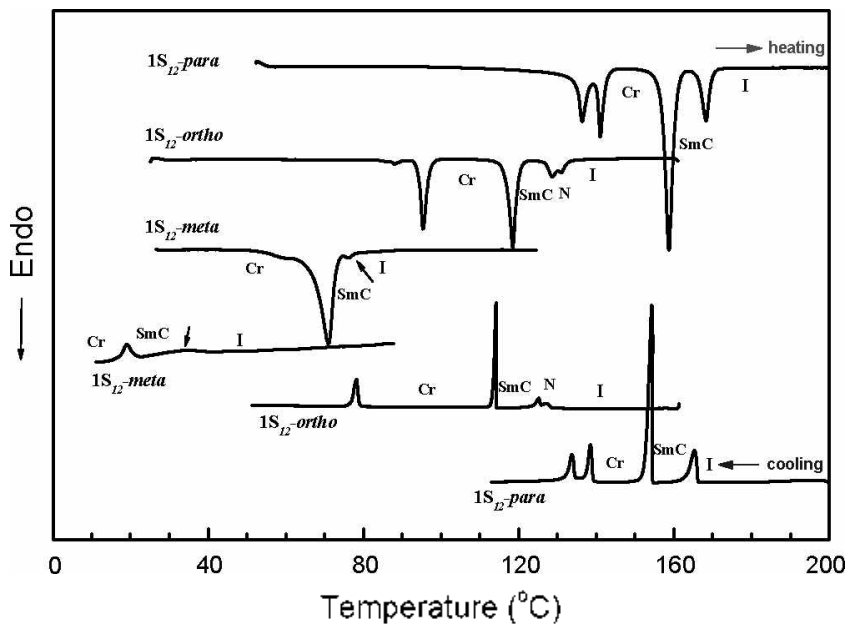

Figure 3. DSC thennogranns of $1 S_{13}$-ortho, -meta and -para compounds.

catalyst in anlydrous EtOH. to yield the target compounds

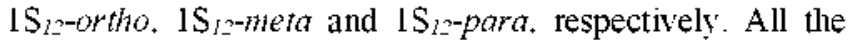
intermediates and the final products were confirmed by elemental analysis. FT-IR. and ${ }^{1} \mathrm{H}$ NMR spectroscopy' (See Figure 2). IR spectra were recorded with a Perkin-Elmer 1000 FT-IR spectrophotometer on $\mathrm{KBr}$ pellets. ${ }^{1} \mathrm{H}-\mathrm{NMR}$ spectra were recorded by using a Varian Mercury $300(300 \mathrm{MHz})$ NMR spectrometer. Differential scanuing calorimetric measurements were performed using a TA instruments 910 S DSC apparatus under dry nitrogen flow at the scanning rates of 10 ${ }^{\circ} \mathrm{C} / \mathrm{min}$. The transition temperatures were taken at the maximum point of the peaks for each sample. The transition enthalpies were evaluated from the integrated area of the endothernic peaks using a reference indium sample as the standard. Optical microscopy observation was carried out using a Nikon Labophot-2 polarizing microscope fitted with a RTC-1 temperature controller (Instec Inc.. Broomfield. Co.) and a Mettler FP-82HT hot stage.

Figure 3 represents the DSC thermodiagrams obtained for both the heating and cooling traces. In Table 1 are summarizes the phase transitions and associated enthalpy changes of
Table 1. Phases transition temperatures of the synthesized compounds: $\mathrm{Cr}=$ crystalline state, $\operatorname{Sin} \mathrm{C}=$ smectic $\mathrm{C}, \mathrm{N}=$ nematic, $\mathrm{I}=$ isotropic state.

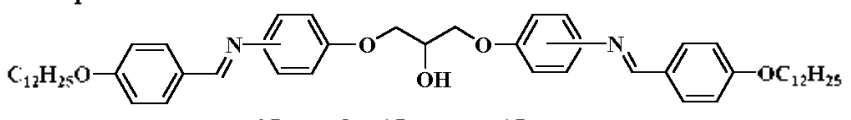

$1 \mathrm{~S}_{12-o r t h o,} 1 \mathrm{~S}_{12-m e r a, 1 \mathrm{~S}_{12} \text { para }}$

\begin{tabular}{|c|c|c|}
\hline & \multirow{2}{*}{$\begin{array}{l}\text { Phase and transition temperatures } /{ }^{\circ} \mathrm{C} \\
\qquad(J \mathrm{H}, \mathrm{kJ} / \mathrm{mol})\end{array}$} & Heating \\
\hline & & Cooling \\
\hline \multirow{2}{*}{$1 \mathrm{~S}_{12-p a r a}$} & \multicolumn{2}{|c|}{ Cr $158.7(27.5) \mathrm{SmC} 168.3(14.4) \mathrm{I}$} \\
\hline & \multicolumn{2}{|l|}{ I $165.2(15.1) \mathrm{SmC} 154.3(59.1) \mathrm{Cr}$} \\
\hline \multirow{2}{*}{$1 \mathrm{~S}_{I}-$-ontho } & \multicolumn{2}{|c|}{$\mathrm{Cr} 118.5(49.5) \mathrm{SmC} 128.7(15.5) \mathrm{N} 130.9(7.1) \mathrm{I}$} \\
\hline & \multicolumn{2}{|c|}{ I $127.0(6.5) \mathrm{N} 125.1(14.4) \mathrm{SmC} 114.2(49.3) \mathrm{Cr}$} \\
\hline \multirow{2}{*}{$1 \mathrm{~S}_{I-\text {-neta }}$} & \multicolumn{2}{|l|}{$\mathrm{Cr} 71.0(83.5) \mathrm{SmC} 76.1(1.0) \mathrm{I}$} \\
\hline & \multicolumn{2}{|l|}{ I 34.1 (7.8) SmC 19.1 (21.2) Recr } \\
\hline
\end{tabular}

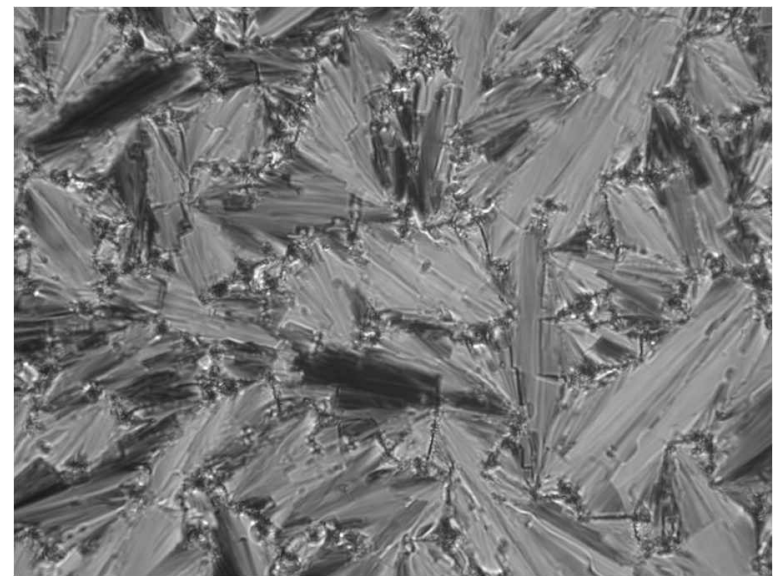

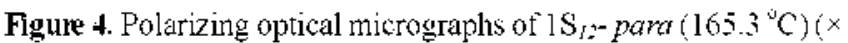
100 ).

dimesogens through the crystalline, smectic and nematic transitions. The compound IS $S_{I-}$-para shows an enantiotropic SmC phase ((Fig. 4). broken fan-shaped texture) similarly to the results in the $2 \mathrm{~S}_{\text {in }}$ series. ${ }^{8}$

When compared to the $1 \mathbf{S}_{I_{-}}$-para compound the clearing and melting points of the $1 \mathrm{~S}_{12}=$ meta decrease by about $92^{\circ} \mathrm{C}$ and $88{ }^{\circ} \mathrm{C}$ respectively. The changes in the phase transition temperatures can be ascribed to the modification of the atomic configurations: The linking position between mesogens and spacer changes from the meta in the the $1 \mathrm{~S}_{I_{-}-\text {meta }}$ to the para in the $1 \mathrm{~S}_{1:-p a r a}$. Due to this molecular configuration chara-

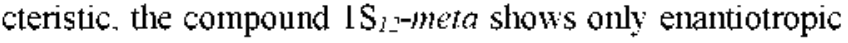
$\mathrm{SmC}$ phase (schlieren texture) of short range order at low temperature. On the while in the $1 \$_{I-}$-ortho having the ortholinking, the clearing and melting points decrease by about 37 ${ }^{\circ} \mathrm{C}$ and $45^{\circ} \mathrm{C}$. respectively. And this compound shows the enantiotropic SmC ((Fig. 5(a). schlieren texture) as well as N ((Fig. 5(b), schlieren texture) phases.

The observation of liquid crystallinity in the U- or V-shaped molecular shape with polymethylene spacer in mesogenic moiety as in $1 \mathrm{~S}_{I_{-}-\text {ortho and }} 1 \mathrm{~S}_{I_{-}-m e t a}$ are firstly reported in 
(a)

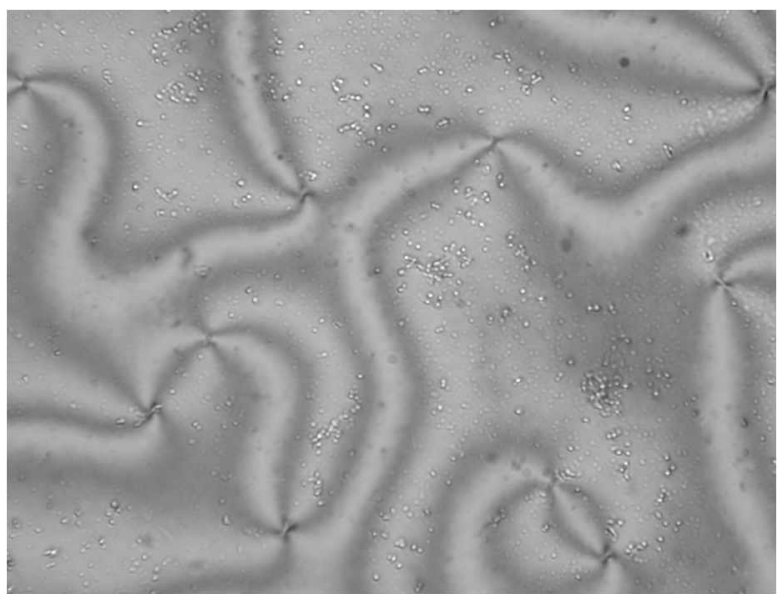

(b)

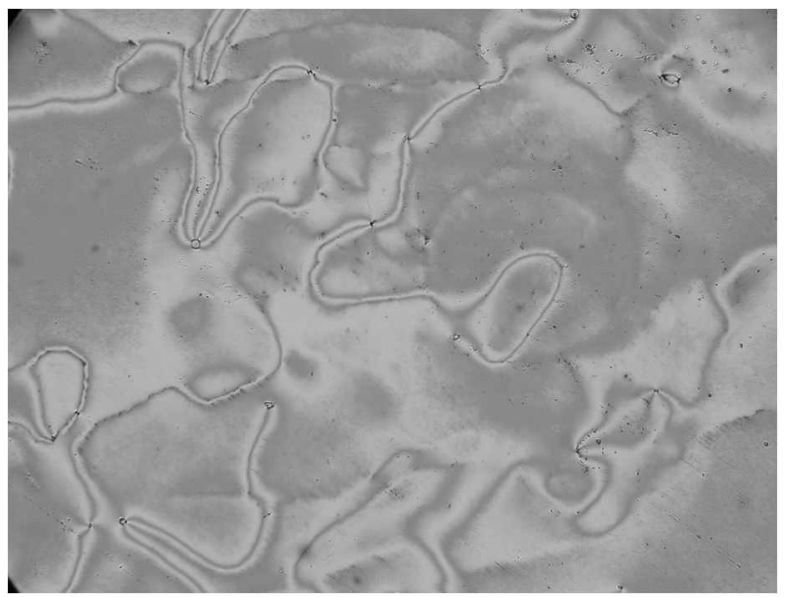

Figure 5. Polarizing optical micrographs of (a) $\operatorname{SinC}\left(124.5^{\circ} \mathrm{C}\right)$ and $(\mathrm{b}) \mathrm{N}\left(129.6^{\circ} \mathrm{C}\right)$ of $1 \mathrm{~S}_{2-}$ ontho $(\times 100)$.

this study. Texture analysis using $\mathrm{X}$-ray diffraction will be carried out to understand the characteristic features of dimers in more detail.

Acknowledgments. The author (J.-H. Park) is grateful for financial support by the academic research fund 2005 of Hoseo University of Korea.

\section{References}

1. Imrie, C. T. Structure and Bonding 1999, 95, 149

2. Date, R. W: Imrie, C. T.; Luckhurst, G. R.: Seddon, T. M. Lia.
Cnust 1992.12.203.

3. Attard, G. S.: Date, R. W.; Imrie, C. T.; Luckhurst, G. R.; Roskilly, S. J.: Seddon, J. M.: Taylor, L. Liq. Civst. 1994, 16. 529.

4. Watanabe $\mathrm{T}$; Komura, H.; Niori, T. Liq. Cnst. 1993, 13, 455.

5. Niori, T.; Adachi, S.; Watanabe, J. Liq. Cryst 1995, 19, 139.

6. (a) So, B.-K.; Tang, M.-C.; Park, J.-H.; Lee, K.-S.; Song, H. H.; Lee, S.M. Opt Aater 2003, 21,685 (b) Kim, W.-T; So, B.-K.; Lee. S.-M. 92nd National heeting of the Kowean Chem. Soc. $2002,92,100$.

7. So, B.-K; Kim, Y.-S; Choi, M.-M.; Lee, S.-M.; Kim, J.-E:; Song, H. H.; Park, T.-H. Liq. Cnst. 2004, 31, 169.

8. So, B.-K.; Kim, W.-I.: Lee, S.-M.: Jang, M.-C.: Song, H.-H.; Park, I.-H. Dyes and Pigment 2007, 75,619. 